\title{
Phenotypic and molecular marker analysis uncovers the genetic diversity of the grass Stenotaphrum secundatum
}

Ying Luo ${ }^{1,2+}$, Xiujie Zhang ${ }^{1,2+}$, Jiahong X ${ }^{1,2+}$, Yao Zheng ${ }^{1,2}$, Shouqin $\mathrm{Pu}^{1,2}$, Zhizhen Duan ${ }^{1,2}$, Zhihao Li ${ }^{1,2}$, Guodao Liu ${ }^{3}$, Jinhui Chen ${ }^{1,2^{*}}$ (D) and Zhiyong Wang ${ }^{1,2^{*}}$

\begin{abstract}
Background: Stenotaphrum secundatum is an important grass with a rich variety of accessions and great potential for development as an economically valuable crop. However, little is known about the genetic diversity of $S$. secundatum, limiting its application and development as a crop. Here, to provide a theoretical basis for further conservation, utilization, and classification of S. secundatum germplasm resources, we used phenotypic and molecular markers (single-nucleotide polymorphisms, SNPs; sequence-related amplified polymorphism, SRAP; intersimple sequence repeat, ISSR) to analyze the genetic diversity of $49 \mathrm{~S}$. secundatum accessions.

Results: Based on seven types of phenotypic data, the $49 \mathrm{~S}$. secundatum accessions could be divided into three classes with great variation. We identified 1,280,873 SNPs in the 49 accessions, among which $66.22 \%$ were transition SNPs and 33.78\% were transversion SNPs. Among these, $C / T$ was the most common (19.12\%) and $\mathrm{G} / \mathrm{C}$ the least common (3.68\%). Using 28 SRAP primers, 267 polymorphic bands were detected from the 273 bands amplified. In addition, 27 ISSR markers generated 527 amplification bands, all of which were polymorphic. Both marker types revealed a high level of genetic diversity, with ISSR markers showing a higher percentage of polymorphic loci (100\%) than SRAP markers (97.8\%). The genetic diversity of the accessions based on SRAP markers $(h=0.47, I=0.66)$ and ISSR markers ( $h=0.45, I=0.64$ ) supports the notion that the $S$. secundatum accessions are highly diverse. $S$. secundatum could be divided into three classes based on the evaluated molecular markers.

Conclusions: Phenotypic and molecular marker analysis using SNP, SRAP, and ISSR markers revealed great genetic variation among $S$. secundatum accessions, which were consistently divided into three classes. Our findings provide a theoretical basis for the genetic diversity and classification of S. secundatum. Our results indicate that SNP, SRAP and ISSR markers are reliable and effective for analyzing genetic diversity in S. secundatum. The SNPs identified in this study could be used to distinguish $S$. secundatum accessions.
\end{abstract}

Keywords: Stenotaphrum secundatum, Phenotype, Molecular markers, Single-nucleotide polymorphism, Genetic diversity

\footnotetext{
* Correspondence: jinhuichen@hainanu.edu.cn;

wangzhiyong@hainanu.edu.cn

†Ying Luo, Xiujie Zhang and Jiahong Xu contributed equally to this work.

${ }^{1}$ Key Laboratory of Genetics and Germplasm Innovation of Tropical Special

Forest Trees and Ornamental Plants, Ministry of Education/Engineering

Research Center of Rare and Precious Tree Species in Hainan Province,

College of Forestry, Hainan University, Haikou 570228, People's Republic of

China

Full list of author information is available at the end of the article
}

C C The Author(s). 2020 Open Access This article is licensed under a Creative Commons Attribution 4.0 International License, which permits use, sharing, adaptation, distribution and reproduction in any medium or format, as long as you give appropriate credit to the original author(s) and the source, provide a link to the Creative Commons licence, and indicate if changes were made. The images or other third party material in this article are included in the article's Creative Commons licence, unless indicated otherwise in a credit line to the material. If material is not included in the article's Creative Commons licence and your intended use is not permitted by statutory regulation or exceeds the permitted use, you will need to obtain permission directly from the copyright holder. To view a copy of this licence, visit http://creativecommons.org/licenses/by/4.0/. The Creative Commons Public Domain Dedication waiver (http://creativecommons.org/publicdomain/zero/1.0/) applies to the data made available in this article, unless otherwise stated in a credit line to the data. 


\section{Background}

Stenotaphrum is a perennial Poaceae genus in the Gramineae family. This genus, comprising eight species, is widely distributed in the Pacific Islands, Africa, and the Americas [1]. Stenotaphrum secundatum is a warmseason grass species commonly utilized in the turfgrass industry. Compared with other warm-season turfgrasses, $S$. secundatum is known for its tolerance to shade [2], drought [3], and disease [4]. Within Stenotaphrum, S. secundatum has strong adaptability to various soil conditions and resistance to moisture and flooding, making it particularly suitable for planting in urban regions and in lawns in humid, low-lying areas [5]. In addition, $S$. secundatum exhibits the ability to trail, strong regenerative capacity, and rapid reproduction, suggesting it could be used for soil and water conservation in warm regions and for the greening of barren hills. S. secundatum can be easily managed at low cost, supporting its use as a commercial warm-season lawn grass [5]. All these characteristics make $S$. secundatum a valuable turfgrass.

Previous studies of $S$. secundatum have mainly focused on its ecological habits and morphological characteristics. S. secundatum has abundant genetic polymorphisms $[6,7]$, but little is known about the genetic relationships and diversity of $S$. secundatum accessions. A few studies have focused on the genetic diversity of S. secundatum germplasm using amplified fragment length polymorphism (AFLP) [8] and simple sequence repeat (SSR) markers [7]. Genovesi et al. [9] used EST-derived microsatellites (EST-SSRs) to identify heterozygosity and evaluate genetic variation in $25 \mathrm{~S}$. secundatum lines obtained from ploidy crosses. Yu et al. [10] used 2871 SNPs and 81 SSRs to develop a high-density genetic map of S. secundatum and identified putative quantitative trait loci (QTL) related to turf quality.

Molecular markers are excellent tools for exploring the genetic diversity of different plants, especially for classifying species that are difficult to identify using traditional classification methods [11]. Molecular markers are also useful for analyzing the evolutionary relationships between different plant groups [12]. A wide variety of molecular marker types have been employed to evaluate the genetic diversity of grasses, including SNP [13], ISSR [14, 15], and SRAP [16] markers. SNPs refer to single-nucleotide differences in the genomic DNA sequences of different organisms. The advantages of SNPs are that they contain only single-nucleotide variations, are widely distributed, and show high genetic stability [17]. SNPs have been successfully used to analyze the genetic diversity of Nicotiana tabacum and Triticum aestivum [18, 19]. Li et al. [20] used SNP markers to analyze 59 cabbage varieties and identified 417 SNPs that were used as core markers to construct DNA fingerprints in order to obtain SNP fingerprints. SNPs were also used to identify 105 maize inbred lines by genotyping point mutations [21].

Here, we performed statistical analysis of seven phenotypic traits in a panel of $S$. secundatum accessions and analyzed their genetic diversity using SNP, SRAP, and ISSR markers, elucidating the genetic diversity within $S$. secundatum. We compared genetic differences among accessions from different sources to identify good germplasm resources, providing a theoretical basis for breeding excellent individuals and laying the foundation for the conservation and utilization of S. secundatum.

\section{Results}

\section{S. secundatum resources exhibit abundant phenotypic diversity}

Analysis of seven phenotypic traits in 49 S. secundatum accessions showed that plants from different regions exhibited extensive phenotypic variation. The average coefficient of variation (CV) of the seven phenotypic traits was $15.71 \%$. The CV was highest for height of the erect shoot $(25.82 \%)$, followed by leaf length of the erect shoot, stolon length, and leaf width of the erect shoot. The variation in leaf color (from yellow-green to darkgreen) was small. The CV values for leaf length of the erect shoot and erect shoot height were $>20 \%$ (Additional file 1: Table S1).

Principal component analysis (PCA) (Additional file 2: Figure S1) showed that the cumulative contribution of all three principal components was as high as $81.38 \%$, which basically represents the comprehensive variation of all seven traits. The contribution ratio of the first principal component was $56.23 \%$, with the highest input from height of the erect shoot, leaf length of the erect shoot, and length of the stolon, indicating that these three morphological traits are the most important variable factors in the phenotypic diversity of S. secundatum. The contribution ratios of the second and third principal components were 15.87 and $9.28 \%$, respectively, with the highest input from leaf width of the erect shoot and turf quality.

We estimated the correlation coefficients between the seven phenotypic traits by correlation analysis (Table 1 ). There was a positive correlation between leaf length of the erect shoot and stolon length $(" P<0.05)$. Stolon diameter was positively correlated with leaf width of the erect shoot $\left({ }^{* *} P<0.01\right)$ and negatively correlated with stolon length $\left({ }^{* * *} P<0.01\right)$. The height of the erect shoot was positively correlated with leaf length of the erect shoot and stolon length $\left({ }^{* * *} P<0.01\right)$. There was a highly positive correlation between turf quality and leaf color $\left({ }^{* * n} P<0.01\right)$. The highest correlation coefficient was 0.696 for height of the erect shoot and leaf length of the erect shoot. 
Table 1 Analysis of the correlation among phenotypic characteristics of the S. secundatum accessions $(n=49)$

\begin{tabular}{|c|c|c|c|c|c|c|c|}
\hline & $\begin{array}{l}\text { Leaf width of the } \\
\text { erect shoot }(\mathrm{cm})\end{array}$ & $\begin{array}{l}\text { Leaf length of the } \\
\text { erect shoot }(\mathrm{cm})\end{array}$ & $\begin{array}{l}\text { Length of the } \\
\text { stolon }(\mathrm{cm})\end{array}$ & $\begin{array}{l}\text { Diameter of the } \\
\text { stolon }(\mathrm{mm})\end{array}$ & $\begin{array}{l}\text { Height of the } \\
\text { erect shoot }(\mathrm{cm})\end{array}$ & $\begin{array}{l}\text { Leaf } \\
\text { color }\end{array}$ & $\begin{array}{l}\text { Turf } \\
\text { quality }\end{array}$ \\
\hline $\begin{array}{l}\text { Leaf width of the } \\
\text { erect shoot }(\mathrm{cm})\end{array}$ & 1 & & & & & & \\
\hline $\begin{array}{l}\text { Leaf length of the } \\
\text { erect shoot }(\mathrm{cm})\end{array}$ & 0.215 & 1 & & & & & \\
\hline $\begin{array}{l}\text { Length of the } \\
\text { stolon }(\mathrm{cm})\end{array}$ & -0.186 & $0.310^{\mathrm{a}}$ & 1 & & & & \\
\hline $\begin{array}{l}\text { Diameter of the } \\
\text { stolon }(\mathrm{mm})\end{array}$ & $0.567^{b}$ & 0.096 & $-0.426^{b}$ & 1 & & & \\
\hline $\begin{array}{l}\text { Height of the } \\
\text { erect shoot }(\mathrm{cm})\end{array}$ & 0.215 & $0.696^{b}$ & $0.609^{b}$ & -0.084 & 1 & & \\
\hline Leaf color & 0.137 & 0.109 & -0.113 & -0.094 & 0.066 & 1 & \\
\hline Turf quality & 0.161 & 0.054 & -0.037 & -0.169 & -0.074 & $0.598^{b}$ & 1 \\
\hline
\end{tabular}

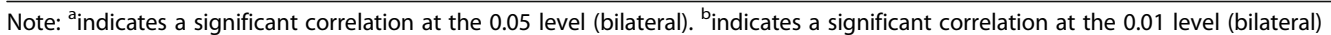

Based on these seven phenotypic traits, we performed cluster analysis with SPSS 22.0. Cluster analysis divided the $49 \mathrm{~S}$. secundatum accessions into three classes (Classes $\mathrm{A}, \mathrm{B}$, and $\mathrm{C}$ ) at a Euclidean distance of 7.5 (Fig. 1). Class A contained 23 accessions (S02, S03, S18, S08, S15, S23, S19, S37, S07, S28, S22, S27, S06, S35, S36, S24, S39, S20, S21, S04, S38, S12, and S88) with short leaf length of the erect shoot, short height of the erect shoot, and low turf quality. Class B included 14 accessions (S13, S14, S46, S85, S53, S54, S47, S25, S50, S26, S51, S52, S49, and S48) with short leaf length of the erect shoot, short height of the erect shoot, and high turf quality. Class $\mathrm{C}$ included 12 accessions with longer leaf length of the erect shoot and higher height of the erect shoot, including three with shorter stolons (S05, S86, and S31) and nine with longer stolons (S09, S29, S30, S42, S43, S40, S41, S11, and S44).

\section{Genetic diversity and genetic relationships of $S$. secundatum accessions based on SNP analysis}

To ensure the quality of the data, we performed quality control on the original data and reduced data noise through data filtering to obtain high-quality clean reads for subsequent analysis (Additional file 1: Table S2). We obtained 396,610,302 reads from the 49 accessions after filtration, with the number of reads per accession ranging from 2,830,814 to $18,264,310$ (Additional file 1: Table S3) and averaging 8,094,088. The sequencing quality value (Q30) ranged from 87.45 to $92.24 \%$, with an average value of $89.16 \%$. The GC content obtained by sequencing ranged from 42.07 to $45.35 \%$, with an average value of $43.26 \%$. The Q30 values of all accessions were greater than $80 \%$, indicating that the string error rate was low and the data were of high quality. The GC content was ubiquitous, indicating that the requirements were met. A total of 1,844,338 restriction-site associated DNA tags (RAD-tags) were developed for the $49 \mathrm{~S}$. secundatum accessions, and 1,280,873 SNP tags were developed using RAD-tags. These SNPs included $66.22 \%$ transition SNPs and 33.78\% transversion SNPs (Additional file 2: Figure S2). Among these, $\mathrm{C} / \mathrm{T}$ was the most common (19.12\%) and G/C the least common (3.68\%).

We used Frappe1.1 to cluster the $49 \mathrm{~S}$. secundatum accessions based on the 1,280,873 SNPs in the filtered reads populations (Fig. 2). From $\mathrm{K}=2-5$, S18, S20, S38, S46, S48, S49, S50, S51, S52, S53, S54, and S85 were always clustered in the same class, indicating that their genetic relationship was relatively close. S02, S06, S11, S15, S19, S36, S40, S41, S42, S43, S44, and S35 were always clustered in the same class, indicating that their genetic relationship was close, whereas S09, S08, S03, S31, S05, and S27 were clearly separated from the other accessions, indicating that their genetic relationship was more distant.

We generated a distance matrix and constructed a clustering diagram of the 49 accessions based on the 1 , 280,873 SNPs in the filtered population (Fig. 3). The 49 $S$. secundatum accessions were divided into three classes in the clustering diagram. Class A contained 13 accessions, including four accessions from Hainan (S02, S28, S03, and S24), four from Guangxi (S08, S05, S37, and S19), two from Yunnan (S27 and S13), one from Fujian (S25), one from Guangdong (S26), and one from the Vanuatu (S88). Class B contained 32 accessions, including nine accessions from Hainan (S04, S48, S85, S20, S12, S36, S21, S11, and S39), eight from Guangxi (S38, S18, S09, S41, S40, S42, S43, and S44), eight from Fujian (S49, S53, S51, S54, S50, S52, S22, and S23), four from Guangdong (S46, S35, S06, and S07), two from Yunnan (S15 and S14), and one from Jiangsu (S47). Class C contained four accessions, including two accessions from Hainan (S29 and S30), one from Guangdong (S86), and one from Yunnan (S31).

PCA (Additional file 2: Figure S3) of the 49 accessions revealed that S40, S41, S42, S43, and S44 were clustered 


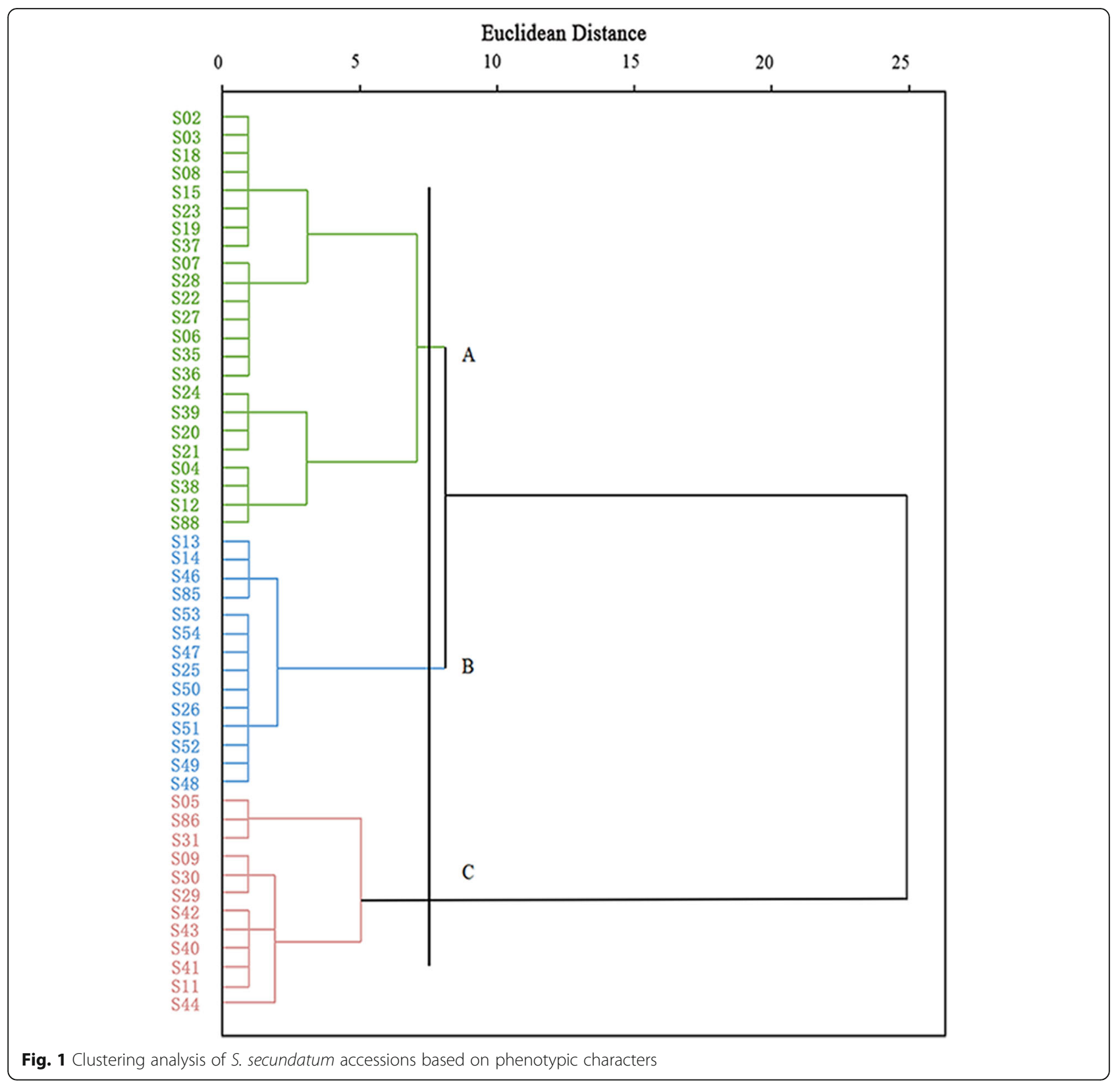

together and were significantly separated from the other accessions. S02, S27, and S28 were clustered together and separated from the other accessions. S03 was grouped in a single class, whereas most accessions were grouped together. The results of PCA were congruent with the results of cluster analysis and structural clustering in that they clearly showed the relationships among accession pedigrees.

\section{Genetic diversity and genetic relationships of $S$.} secundatum accessions based on SRAP analysis

We amplified S. secundatum DNA using 28 pairs of SRAP polymorphic primers and consistently obtained 273 clear, bright bands, including 267 polymorphic bands, with a polymorphism rate of $97.8 \%$. Each pair of primers amplified six to 13 bands (Additional file 1: Table S4). Additional file 2: Figure S4 shows the spectra of amplified bands from $46 \mathrm{~S}$. secundatum accessions obtained using Primer EM14-ME4. The amplified DNA bands ranged from 200 to $400 \mathrm{bp}$, and the ratio of polymorphic bands amplified by each pair of primers was $87.5-100 \%$. Thus, the SRAP markers in S. secundatum showed abundant polymorphism. We used PopGen32 to analyze the genetic diversity of the $46 \mathrm{~S}$. secundatum accessions. The average Nei's genetic diversity $(h)$ value of the accessions was 0.47 , and the average Shannon's information index $(I)$ was 0.66 


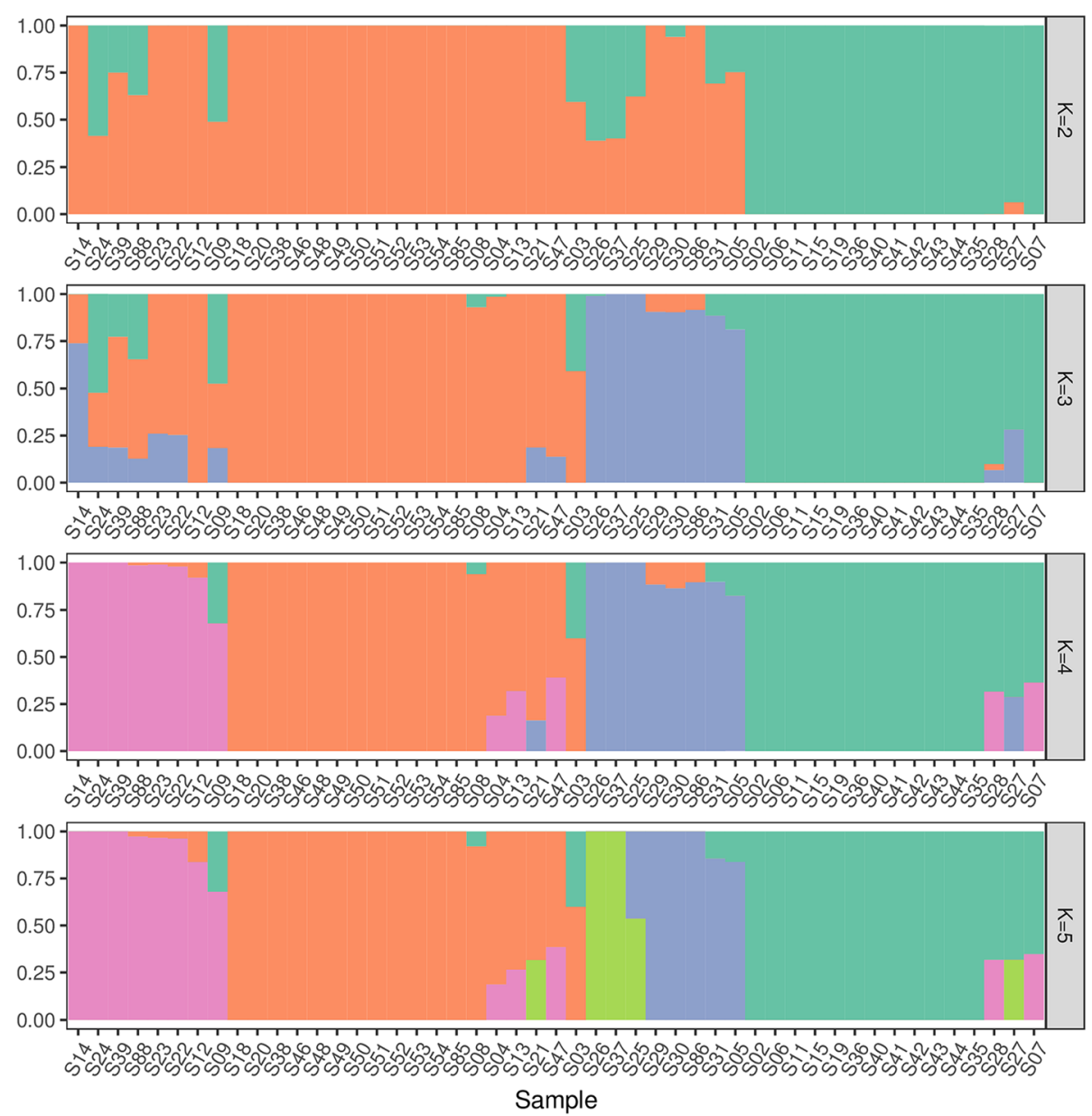

Fig. 2 Structural clustering of 49S. secundatum accessions (cultivars) based on SNP data

(Additional file 1: Table S5). Both values were relatively high, indicating that there was great variation and rich genetic diversity among different $S$. secundatum germplasms. The genetic similarity coefficients of the materials ranged from 0.36 to 0.84 (Additional file 1: Table S6). The genetic similarity coefficient between $\mathrm{S} 40$ and S43, which were both from Guangxi, was 0.84 , indicating that their relationship was the closest. The genetic similarity coefficient between S09 from Hainan and S26 from Guangdong was the smallest, indicating that they had a distant genetic relationship.

UPGMA (Unweighted Pair Group Method with Arithmetic means) clustering (Fig. 4) of the $46 \mathrm{~S}$. secundatum accessions showed that S02 from Hainan and S36 from Fujian were the furthest apart in the clustering diagram, with the 44 remaining accessions distributed between them. UPGMA clustering also divided the 46 accessions into three classes (Class A, B, and C), with a similarity coefficient of 0.59. Class A contained 34 S. secundatum accessions, which were all S. secundatum var. 'Variegatum' (S04, S48, S20, S21, S38, and S12). Class A was divided into subclasses I, II, and III. Subclass I contained 18 accessions, including six accessions from Guangxi (S05, S08, S40, S42, S43, and S37), five from Hainan (S02, S11, S24, S28, and S29), four from Guangdong (S06, S07, S35, and S26), two from Yunnan (S15 and S27), and one from Fujian (S25). Subclass II contained 13 accessions, including five accessions from Hainan (S03, S04, S48, S20, and S21), two from Yunnan (S13 and S14), two from Guangxi (S18 and S38), two from Fujian (S22 and S23), one from Guangdong (S46), and one from Jiangsu (S47). Subclass III contained two accessions from Hainan (S12 and S30) and S31 from Yunnan. Class B contained six accessions, which were all from Fujian (S49, S50, S51, S53, S52 and S54). Class C contained six accessions (S09, S44, S39, S41, S19 and S36), including four accessions from Hainan and two from Guangxi.

\section{Genetic diversity and genetic relationships of $S$. secundatum accessions based on ISSR analysis}

We also analyzed the genetic diversity of the $46 \mathrm{~S}$. secundatum accessions using 27 ISSR primers. In total, 527 bands 


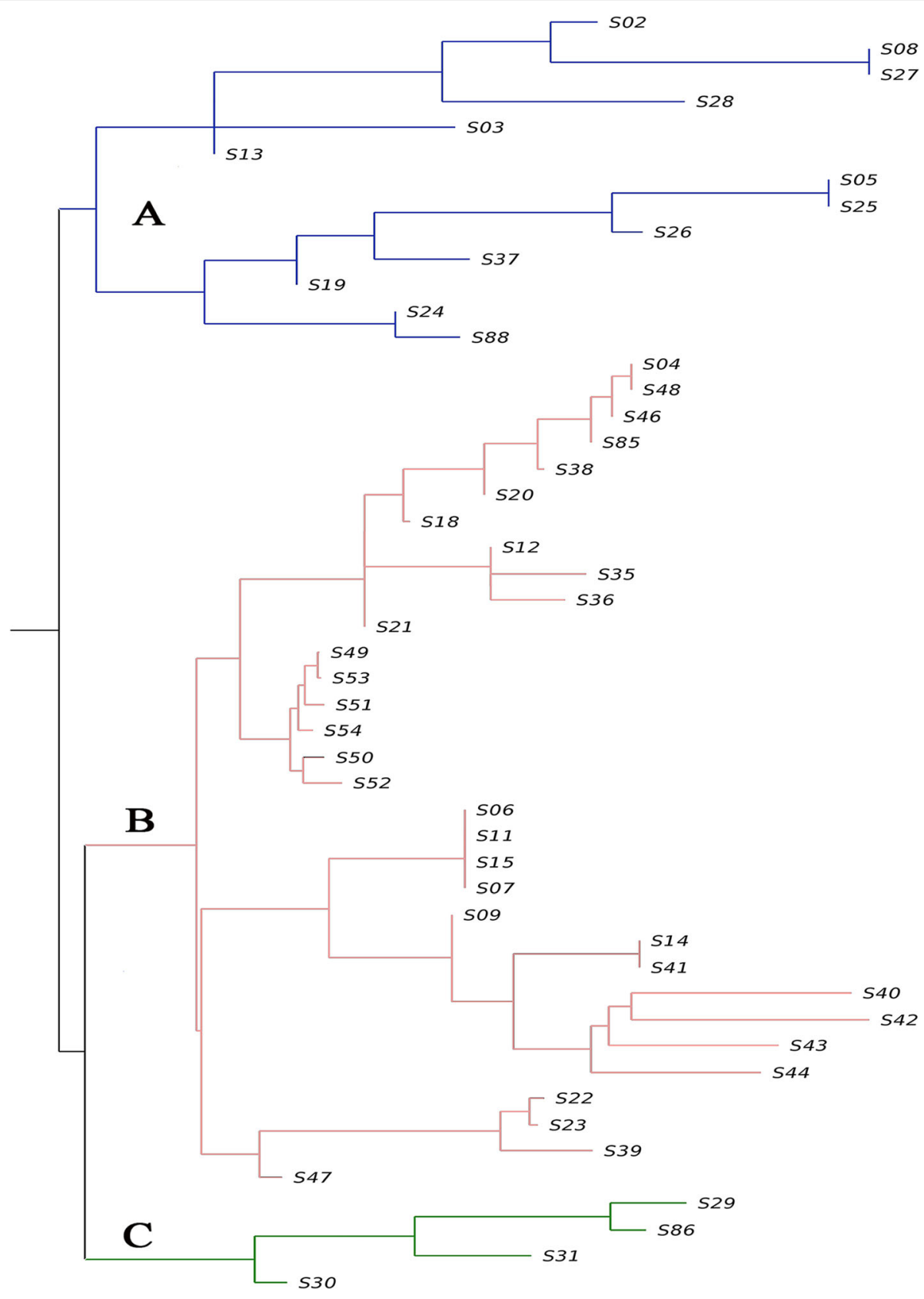

Fig. 3 Neighbor-joining clustering of 49 S. secundatum accessions (cultivars) based on SNP data

were amplified, which all were polymorphic. The average number of bands amplified by each primer was 19.52, with 14 to 25 bands amplified per primer (Additional file 1: Table S7), indicating that $S$. secundatum shows abundant ISSR polymorphism. Additional file 2: Figure S5 shows the spectra of amplified bands from the $46 \mathrm{~S}$. secundatum accessions obtained using Primer ISSR889. PopGen32 was used to analyze their genetic diversity. The $h$ value of the 46 accessions was 0.45 , and the $I$ value was 0.64 (Additional file 1: Table S8). Both values are relatively high, indicating that there was great variation and rich genetic diversity in the S. secundatum germplasm. These results indicate that ISSR markers could be successfully used to reveal the genetic differences among germplasm resources.

The genetic similarity coefficient of $S$. secundatum was 0.50-0.84 (Additional file 1: Table S9), indicating that the materials had rich genetic diversity. The genetic similarity coefficient between S52 and S53 was 0.84, indicating that their relationship was the closest. The genetic similarity coefficient between S04 from Hainan and S35 from Guangdong was 0.50, indicating that they had a distant genetic relationship. UPGMA clustering of the 


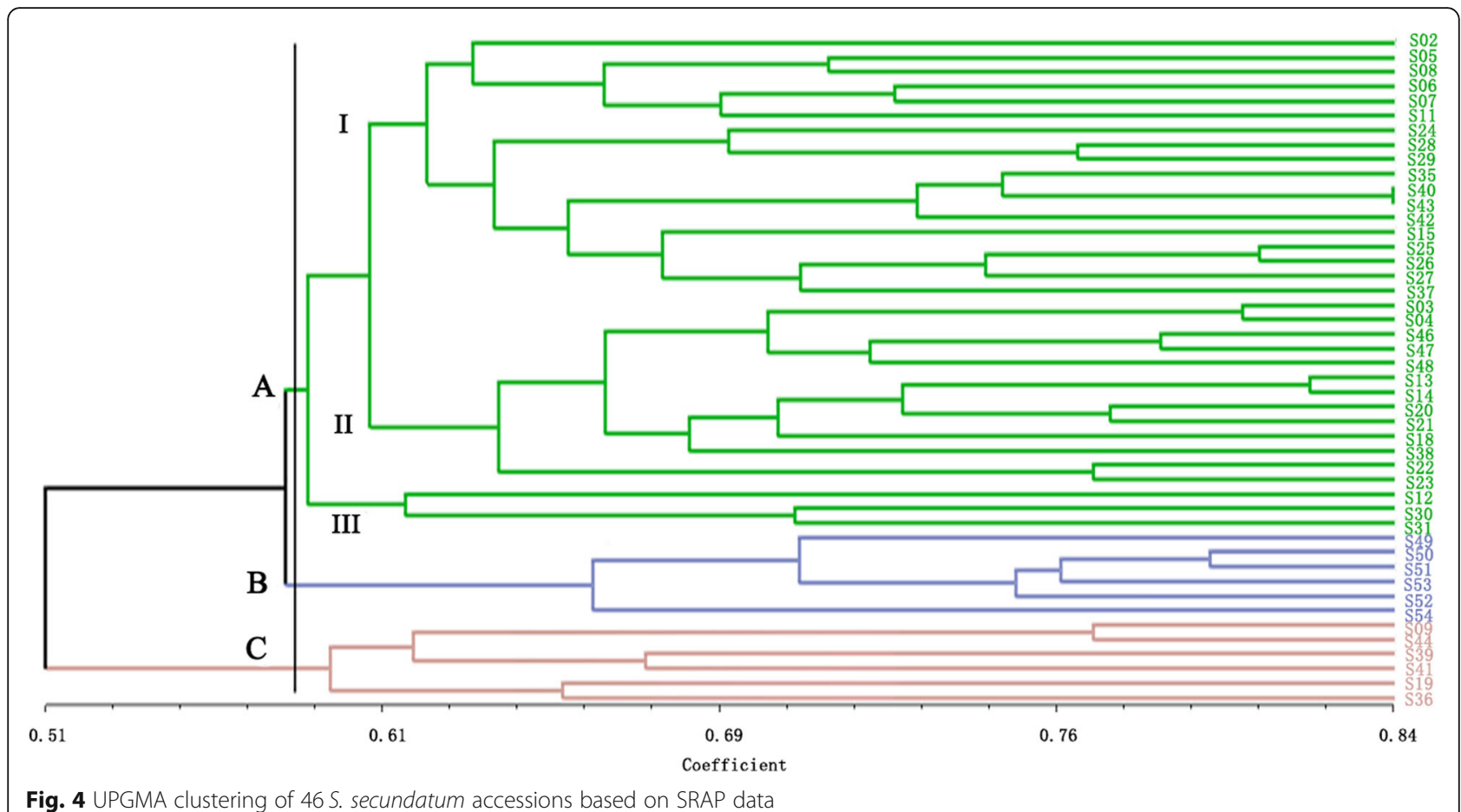

46 S. secundatum accessions showed that S02 and S41 were the furthest apart in the clustering diagram, with the 44 remaining germplasm resources distributed between them (Fig. 5). UPGMA clustering also divided the 46 accessions into three classes (Class A, B, and C), with a similarity coefficient of 0.60 . Class A contained 25 accessions, including nine accessions from Hainan
(S02, S03, S04, S11, S12, S24, S28, S20, and S21), six from Guangxi (S05, S08, S09, S18, S19, and S38), four from Yunnan (S13, S14, S15, and S27), three from Guangdong (S06, S07, and S26), and three from Fujian (S22, S23, and S25). Class B contained six accessions (S49, S50, S51, S53, S52, and S54), and Class C contained 10 accessions, including four accessions from

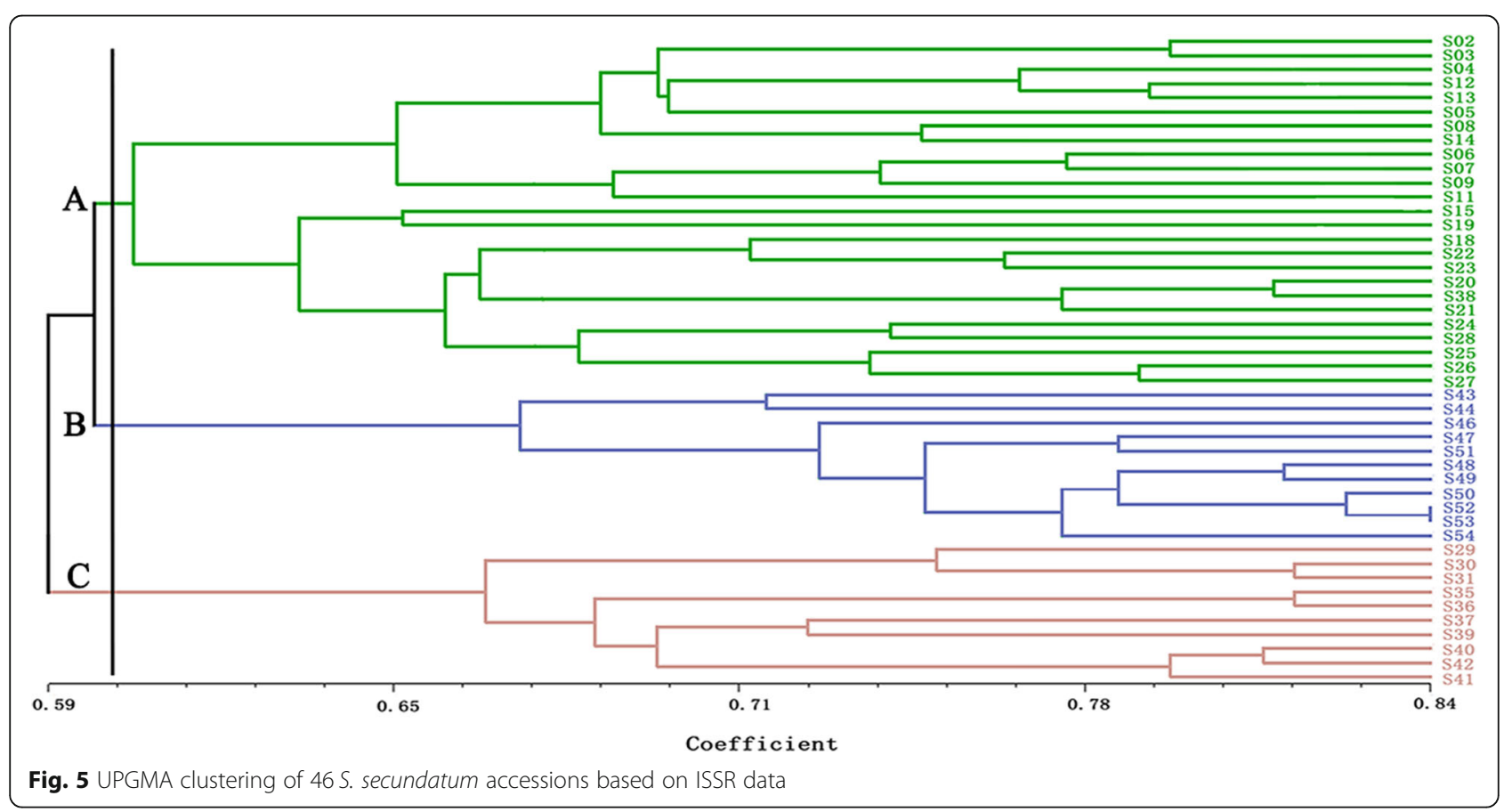


Guangxi (S37, S40, S41, and S42), four from Hainan (S29, S30, S36, and S39), one from Yunnan (S31), and one from Guangdong (S35).

\section{Discussion}

\section{S. secundatum accessions show high levels of variation}

The phenotypes of the S. secundatum accessions examined in the current study covered a larger range of variation than those examined previously [22]. Indeed, the phenotypes of the S. secundatum accessions showed great variability, providing a basis for the multiple uses of $S$. secundatum. Among the $49 \mathrm{~S}$. secundatum germplasm resources examined here, the grass turf quality was high for many accessions (such as S47, S48, S49, S50, S51, S52, S53, and S54), indicating that they could be used as turfgrass breeding materials. Various $S$. secundatum accessions (such as S09, S11, S40, S41, and S44) had long and wide leaves and long stolon internodes, indicating that they could be used as breeding materials for solid soil slope protection in lawns or pastures. In summary, the availability of abundant S. secundatum resources could facilitate the selection and breeding of fine turfgrasses with broad applications and high economic potential.

From the perspective of modern genetics, species with higher genetic diversity will have a wider natural distribution and stronger environmental adaptability, survivability, and evolutionary potential than other species. Genetic variation is required for a species to adapt to environmental changes [23]. Therefore, evaluating genetic diversity is an important part of germplasm identification and collection. In the current study, the ISSR markers provided more informative data than SRAP markers. Similar results have been obtained for Elymus pastures [24], tobacco [25], and Grifola frondosa [26] using ISSR and SRAP molecular markers. Overall, though our SRAP and ISSR markers returned higher $S$. secundatum species diversity numbers than those previously reported values for other species, such as Pennisetum ( $h=0.3306, I=0.5017$ ) obtained using SRAP markers [27] and Stylosanthes $(h=0.2279, I=0.3553)$ obtained using ISSR markers [28]. We conclude that SRAP and ISSR markers can effectively used to reveal the polymorphism between $S$. secundatum accessions, with high labeling efficiency.

The SNPs uncovered in this study represent the largest number of SNPs for S. secundatum identified to date, revealing large intraspecific differences. These types of SNPs could be used for population-level evolutionary analysis. However, the $1,280,873$ SNPs obtained in the current study are not sufficient for this purpose. We will continue to collect more germplasm and analyze the association between phenotypes and SNPs to identify variations associated with important traits. These SNP markers could also provide a basis for the development of SNP markers in other species of Stenotaphrum.

Analyses based on phenotypic traits and SNP, SRAP, and ISSR markers divide $S$. secundatum from China into three classes

In the present study, the $S$. secundatum accessions clustered into three classes based on seven phenotypic traits. In addition to using phenotypic markers, we used three types of molecular markers (SNP, SRAP, and ISSR markers) to comprehensively analyze the genetic diversity of S. secundatum. Cluster analysis based on phenotypes and on three types of molecular markers produced consistent results, with some minor differences: in all cases, the accessions were clustered into three classes, and seven accessions of $S$. secundatum (S02, S03, S04, S08, S24, S27, and S28) were clustered into a single group. In our phenotypic and molecular marker clustering of the $49 \mathrm{~S}$. secundatum accessions, most accessions from the same region were clustered into one group, and only a few were placed into different groups, perhaps reflecting the spread of introduced genes or the infiltration of certain genes [29]. Clustering using all three markers classified nine S. secundatum accessions from Fujian into two groups. Four accessions from Guangdong (S06 and S07) and Fujian (S23 and S22) were clustered together and showed similar phenotypes, including low values for height of the erect shoot and leaf width of the erect shoot. Perhaps because these two provinces are adjacent, human activities and natural factors caused these accessions to spread and reproduce in both provinces. Similar observations have been made for other germplasms [30, 31].

Our clustering based on phenotypic and molecular markers produced similar results, indicating that the phenotypic markers and different molecular markers performed convergently. This consistency points to the reliability of our current classification of the genetic diversity of $S$. secundatum based on phenotypic traits. Similarly, 300 Gossypium hirsutum accessions were divided into three classes based on phenotypic traits and SSR markers [32], and 16 Tagetes patula accessions were placed into three classes based phenotypic traits and ISSR markers [33]. These results from a range of species indicate that classification based on phenotypic traits is suitable for genetic diversity analysis.

Clustering can also be used to determine the genetic diversity and genetic relationships between germplasm from different regions. Due to difficulties in obtaining samples, most of our experimental germplasm resources were from China. In another study, AFLP markers were used to detect genetic variants of the $S$. secundatum cultivar 'Raleigh' collected from sod farms across the southern United States [8]. This analysis revealed 
separation between original stocks of 'Raleigh' and some commercial accessions. Little is known about the genetic relationships and diversity of $S$. secundatum accessions. The genetic information obtained in the current study could be a very useful for evaluating the genetic diversity in $S$. secundatum and for future molecular markerassisted breeding programs.

\section{Conclusions}

Seven phenotypes of 49 S. secundatum were comprehensively analyzed and clustered. The phenotypes of $S$. secundatum showed large variation. We used RAD-seq technology to evaluate the $S$. secundatum population and performed simplified genome sequencing, SNP detection, and population-level genetic evolutionary analysis, which indicated that RAD-seq technology could successfully be utilized for $S$. secundatum. We obtained 396,610,302 reads from the 49 S. secundatum accessions by RAD-seq and developed 1,844,338 RAD-tags based on the read information and 1,280,873 SNPs based on the RAD-tags. Overall, our analyses of $49 \mathrm{~S}$. secundatum accessions from China, including phenotypic analysis and DNA molecular marker analysis (SNP, SRAP, and ISSR markers), showed that $S$. secundatum could be divided into three classes. We systematically analyzed the genetic diversity of $S$. secundatum germplasm resources to investigate their genetic relationships, providing a theoretical basis for the classification of $S$. secundatum and laying a scientific foundation for the conservation and utilization of $S$. secundatum germplasm resources.

\section{Methods}

\section{Plant materials and phenotypic analysis}

Forty-nine $S$. secundatum accessions, which were obtained from China and the South Pacific, were analyzed in this study (Additional file 1: Table S10). Of these, 48

$S$. secundatum accessions were collected from different regions of China and one was collected from the Vanuatu, South Pacific. The accessions were grown in Haidian Agricultural Base in Hainan University [19 $31^{\prime}$ $\left.\mathrm{N}, 109^{\circ} 34^{\prime} \mathrm{E}\right]$ with unified management. The base is located in the northern edge of the tropics, with a tropical monsoon climate. The annual average temperature is approximately $22-26^{\circ} \mathrm{C}$ and the annual illumination is approximately $1750-2650 \mathrm{~h}$. The light rate was $50-60 \%$, and the solar radiation intensity was 14,012.2-53,587.4 Lux. There was abundant rainfall, with average annual precipitation of $1815 \mathrm{~mm}$.

The $S$. secundatum accessions were cultured in a plot with an area of $1 \mathrm{~m}^{2}$. Routine management was performed, including watering, fertilization, regular pruning, and cleaning of creeping branches. Young leaves were collected from the 49 accessions, stored in an icebox, and subjected to laboratory analysis in a timely manner.

The leaf width of the erect shoot, leaf length of the erect shoot, stolon length, stolon diameter, height of the erect shoot, leaf color, and turf quality of the $49 \mathrm{~S}$. secundatum accessions were measured as described by Liao et al. and Liu et al. [34, 35]. A vernier caliper was used to measure the width and length of the fourth mature leaf from the top to the base of the erect shoot (Leaf width and length of the erect shoot) and the internode length and diameter of the fourth stem segment of stolon from top to base (Length and diameter of the stolon). A ruler was used to measure the height of the erect shoot. The leaf color was scored (and repeated three times) based on the following criteria: one point for withered yellow lawn or bare land; one to three points for more dead leaves and less green tissue; five points for more green plants and a small amount of dead leaves; five to nine points for lawns from yellow-green to dark green. Based on the indicators of leaf color, texture, density, and uniformity, turf quality was evaluated according to the 5-level standard of external character observations.

SPSS 22.0 was used to calculate the correlation between the seven phenotypic traits and to cluster the $S$. secundatum accessions based on the phenotypic data. The differences between the phenotypes of different materials were expressed as coefficient of variation, $C V(\%)=(S / \bar{X}) \times 1$ 00 , where $\mathrm{S}$ is the standard deviation and $\bar{X}$ is the average value of the individual trait. The F-values were calculated to examine the significance of the observed variation.

\section{DNA extraction and SNP analysis}

DNA was extracted from the 49 leaf samples using a Plant Genomic DNA Kit (DP305-03; Tiangen, Beijing, China). The following steps were used to create a library by enzyme digestion: an equal amount of genomic DNA (100 ng) was incubated with restriction enzymes in a $50 \mu \mathrm{l}$ reaction system at $37^{\circ} \mathrm{C}$ for $1 \mathrm{~h}$, followed by incubation at $65^{\circ} \mathrm{C}$ for $20 \mathrm{~min}$ to inactivate the endonuclease. Each enzyme digestion product was ligated to an adapter with a restriction enzyme sticky end and a barcode label, incubated at $20^{\circ} \mathrm{C}$ for $30 \mathrm{~min}$, and inactivated at $65^{\circ} \mathrm{C}$ for $20 \mathrm{~min}$. The accession containing the adapter was mixed, and the DNA mixture was cut into small bands of $\sim 380 \mathrm{bp}$ using a Covaris DNA ultrasonic interrupter. The fragmented DNA was purified using a Qiagen PCR purification kit (Qiagen, Germany), dissolved in $50 \mu \mathrm{L} \mathrm{EB}$, and stored at $4{ }^{\circ} \mathrm{C}$. The purified DNA was used to construct an Illumina sequencing library with a TruSeq Nano DNA Library Preparation Kit (Illumina, USA), which was sequenced on the Illumina HiSeq 4000 platform (Illumina, USA). 
To ensure the quality of the sequences, we performed quality control on the original data prior to analysis and reduced data noise through data filtering. The filtering steps included the following: remove reads $<50 \mathrm{nt}$ long after trimming 3' sequencing adapters; remove reads with an unknown base $(\mathrm{N})$ ratio $>10 \%$, and remove lowquality reads (number of bases with quality value $\mathrm{SQ} \leq$ 20 accounting for more than $50 \%$ of the entire read).

Q30 and GC content were analyzed using BWA (v0.7.15-r1140) software [36] to ensure the quality of the sequencing data. The reads data from the 49 different samples were clustered, and SAMtools (v1.3.1) software [37] was used to classify and splice reads, connect the reads, and build RAD-tags. GATK (v3.5) software [38] was used for mutation detection: GATK HaplotypeCaller was used to perform SNP calling on each accession, and GATK GenotypeGVCFs was used to merge the SNP results (VCF) from the 49 samples and convert the SNP from the pseudogenomic position back to the original rad sequence position to obtain SNPs. Frappe1.1 software [39] was used to identify the genetic structure of the 49 samples and group lineage information. MEGA 6.0 [40] software was used to calculate the genetic distance with the Kimura distance model and to construct dendrograms with the adjacency method (NJ, Neighbor-Joining). EIGE NSOFT 7.2.0 software [41] was used for PCA.

\section{SRAP-PCR amplification}

The primers were screened based on the principle proposed by Li and Quiro [42] and synthesized by Yingwei Jieji Trading Company (Shanghai). Of the 400 primer pairs examined, 28 pairs generating clear, bright, polymorphic bands were selected and successfully amplified in $46 \mathrm{~S}$. secundatum accessions (Additional file 1: Table S11). The reaction system used for SRAP-PCR amplification included $2.0 \mu \mathrm{l} 5 \times$ buffer, $2.0 \mathrm{mM} \mathrm{Mg}^{2+}, 200 \mu \mathrm{M}$ dNTP, $0.3 \mu \mathrm{M}$ primers, $1.0 \mathrm{U}$ Taq polymerase, $100 \mathrm{ng}$ DNA, and $\mathrm{ddH}_{2} \mathrm{O}$ to a final volume of $10 \mu \mathrm{L}$. The amplification program was as follows: step 1, pre-denaturation at $94{ }^{\circ} \mathrm{C}$ for $5 \mathrm{~min}$, denaturation at $94^{\circ} \mathrm{C}$ for $1 \mathrm{~min}$, annealing at $33^{\circ} \mathrm{C}$ for $1 \mathrm{~min}$, extension at $72{ }^{\circ} \mathrm{C}$ for $60 \mathrm{~s}$; step 1 was repeated for 5 cycles; step 2, denaturation at $94{ }^{\circ} \mathrm{C}$ for $1 \mathrm{~min}$, annealing at $55^{\circ} \mathrm{C}$ for $1 \mathrm{~min}$, extension at $72{ }^{\circ} \mathrm{C}$ for $60 \mathrm{~s}$; step 2 was repeated for 35 cycles; step 3, extension at $72^{\circ} \mathrm{C}$ for $7 \mathrm{~min}$. The final PCR product was stored at $4{ }^{\circ} \mathrm{C}$. After the amplification reaction, the $10 \mu \mathrm{l}$ amplified product was separated on a $10 \%$ nondenaturing polyacrylamide gel using the electrode buffer $1 \times$ TBE for rapid silver staining detection. The DNA

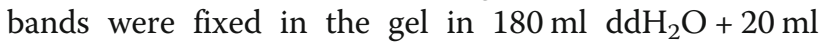
ethanol $+1 \mathrm{ml}$ acetic acid glacial for $12 \mathrm{~min}$ with shak-

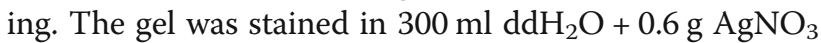
for $12 \mathrm{~min}$ with shaking. After staining, the gel was rinsed for three times with $\mathrm{ddH}_{2} \mathrm{O}$ and incubated in 300
$\mathrm{mL} \mathrm{ddH}_{2} \mathrm{O}+60 \mu \mathrm{L} 10 \%$ sodium thiosulfate for $30 \mathrm{~s}$, followed by developing solution $\left(300 \mathrm{ml} \mathrm{ddH}_{2} \mathrm{O}+4.5 \mathrm{~g}\right.$ $\mathrm{NaOH}+3 \mathrm{ml}$ formaldehyde) until clear bands were obtained. The gel was observed on a film observation lamp and photographed.

\section{ISSR amplification}

ISSR molecular marker [43] analysis was performed using 100 ISSR primers described by the University of British Columbia (S801-S900) and synthesized by Yingwei Jieji Trading Company (Shanghai). The 100 primers were screened by amplifying DNA from two random S. secundatum accessions, and 27 primers producing clear amplification bands with good polymorphism were selected (Additional file 1: Table S12). A previously described reaction system for ISSR PCR amplification $(10 \mu \mathrm{L})$ [44] was used with some modifications: $1.5 \mu \mathrm{L} 10 \times$ buffer $(100 \mathrm{mM}$ Tris- $\mathrm{HCl}$ pH 8.3, $500 \mathrm{mM} \mathrm{KCl}, 15 \mathrm{mM} \mathrm{MgCl}$ ), $200 \mu \mathrm{M}$ dNTPs, $0.3 \mu \mathrm{M}$ primers, $1.0 \mathrm{U}$ Taq polymerase, $100 \mathrm{ng}$ DNA, and $5.1 \mu \mathrm{L} \mathrm{ddH}_{2} \mathrm{O}$ was used for amplification. The amplification program was as follows: step 1, predenaturation at $94{ }^{\circ} \mathrm{C}$ for $5 \mathrm{~min}$; step 2, denaturation at $94{ }^{\circ} \mathrm{C}$ for $1 \mathrm{~min}$, annealing at $55-59^{\circ} \mathrm{C}$ for $1 \mathrm{~min}$, extension at $72{ }^{\circ} \mathrm{C}$ for $90 \mathrm{~s}$; step 2 was repeated for 45 cycles; step 3 , extension at $72{ }^{\circ} \mathrm{C}$ for $7 \mathrm{~min}$. The PCR product was stored at $4{ }^{\circ} \mathrm{C}$. The $10 \%$ gel was

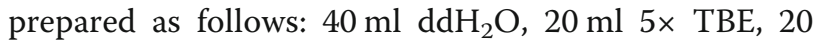
ml 40\% acrylamide, $90 \mu \mathrm{L}$ TEMED, $900 \mu \mathrm{L} 10 \%$ AP. A 3.1-3.3 $\mathrm{L}$ aliquot of each accession was subjected to electrophoresis for $3.5 \mathrm{~h}$ at $120-140 \mathrm{~V}$ and $100 \mathrm{~mA}$.

\section{SRAP and ISSR data analysis}

The presence of a band was assigned a value of " 1 " and its absence was assigned a value of "0"; unclear bands were not included in the analysis. The statistical results were expressed as a $0-1$ matrix, and the data were analyzed with EXCEL, PopGen32 [45], and NTSYS [46]. EXCEL was used to integrate the raw data matrices of SRAP and ISSR markers. PopGen32 was used to calculate the number of polymorphic bands, the percentage of polymorphic loci, the Nei's Gene Diversity, and the Shannon Information Index. NTSYS was used to calculate genetic similarities and to build dendrograms using both the UPGMA [47] and neighbor-joining clustering procedures. Nei's genetic similarity coefficients [48] and cluster analysis were used to determine the genetic distance and genetic diversity among the various $S$. secundatum accessions.

\section{Supplementary information}

Supplementary information accompanies this paper at https://doi.org/10. 1186/s12863-020-00892-W.

Additional file 1: Table S1. Phenotypic characteristics of S. secundatum $(n=49)$. Table S2. Summary of RAD-seq. Table S3. Statistics for raw data 
(RAD-seq) from the 49S. secundatum accessions (cultivar). Table S4. Detailed information on polymorphism revealed by 28 SRAP primer pairs. Table S5. Genetic diversity parameters ( $h$ and I) of $46 \mathrm{~S}$. secundatum accessions based on SRAP markers. Table $\mathbf{S 6}$. Genetic similarity coefficients between 46 S. secundatum accessions based on SRAP data. Table S7. Primer sequences and amplification results of ISSR analysis. Table S8. Genetic diversity parameters ( $h$ and I) of $46 \mathrm{~S}$. secundatum accessions based on ISSR markers. Table S9. Genetic similarity coefficients between $46 \mathrm{~S}$. secundatum accessions based on ISSR data. Table S10. Origins of the 49 S. secundatum accessions examined in this study. Table S11. Primer sequences used for SRAP analysis of S. secundatum. Table S12. Primer sequences used for ISSR analysis of $S$. secundatum.

Additional file 2: Figure S1. Principal component analysis of $49 \mathrm{~S}$ secundatum accessions. The contribution ratios of the first principal component and the second principal component were 56.23 and 15.87\%, respectively. Note: The codes correspond to those listed in Additional file 1: Table S10. Figure S2. Statistics of SNP types in 49 S. secundatum accessions. Figure S3. PCA of $49 \mathrm{~S}$. secundatum accessions (cultivars) based on SNP data. Figure S4. Sample amplification profiles of $46 \mathrm{~S}$. secundatum germplasms based on SRAP primers EM14-ME4. M: 100 bp marker. Note: The codes correspond to those listed in Additional file 1: Table S10. Figure S5. Sample amplification profiles of $46 \mathrm{~S}$. secundatum germplasms based on ISSR primer ISSR889. M: 100 bp marker. Note: The codes correspond to those listed in Additional file 1: Table S10.

\section{Abbreviations}

AFLP: Amplified fragment length polymorphism; CV: Coefficient of variation; EST-SSR: EST-derived microsatellites; $h$ : Nei's gene diversity; I: Shannon information index; ISSR: Inter-simple sequence repeat; NJ: Neighbor-Joining; PCA: Principal component analysis; QTL: Quantitative trait loci; RADSeq: Restriction-site associated DNA sequencing; RAD-tags: Restriction-site associated DNA tags; SNPs: Single-nucleotide polymorphisms; SRAP: Sequence-related amplified polymorphism; SSR: Simple sequence repeat; UPGMA: Unweighted pair group method with arithmetic means

\section{Acknowledgements}

Not applicable.

\section{Authors' contributions}

$J C$ and $Z W$ designed the research. $Y L, X Z, J X, Y Z, S P, Z D$, and $Z L$ performed research. JC, YL, XZ, and JX analyzed and interpreted the data and wrote the paper. GL and ZW critically revised the article. All authors commented on the manuscript. The authors read and approved the final manuscript.

\section{Funding}

This work was supported by the National Natural Science Foundation of China (31560564), the National Natural Science Foundation of China (31960321), and the Scientific Research Fund Project of Hainan University (KYQD(ZR)1830). The funding bodies played no role in the design of the study and collection, analysis, and interpretation of data and in writing the manuscript.

\section{Availability of data and materials}

All relevant datasets supporting the conclusions of this article are available within the article and in Additional files. The raw sequence data reported in this paper have been deposited in the Genome Sequence Archive (Genomics, Proteomics and Bioinformatics, 2017) in BIG Data Center under accession number CRA002158 and are publicly accessible at http://bigd.big. ac.cn/gsa/s/8uHDmiy8. The SNP data are available in VCF under accession number GVM000057 and are publicly accessible at http://bigd.big.ac.cn/gvm/ getProjectDetail?project=GVM000057.

\section{Ethics approval and consent to participate}

Ethics approval is not applicable. No specific permission was required for sampling activities.

\section{Consent for publication}

Not applicable.

\section{Competing interests}

The authors declare that they have no competing interests.

\section{Author details}

${ }^{1}$ Key Laboratory of Genetics and Germplasm Innovation of Tropical Special Forest Trees and Ornamental Plants, Ministry of Education/Engineering Research Center of Rare and Precious Tree Species in Hainan Province, College of Forestry, Hainan University, Haikou 570228, People's Republic of China. ${ }^{2}$ Hainan Biological Key Laboratory for Germplasm Resources of Tropical Special Ornamental Plants, College of Forestry, Hainan University, Haikou 570228, People's Republic of China. ${ }^{3}$ Chinese Academy of Tropical Agricultural Science, Haikou 570228, People's Republic of China.

Received: 21 April 2020 Accepted: 21 July 2020

Published online: 12 August 2020

\section{References}

1. Chen S, Phillips SM. The flora of China. Beijing: Science Press Beijing; 2006

2. Busey P. Genetic diversity and vulnerability of St. Augustinegrass. Crop Sci. 1995;35(2):322. https://doi.org/10.2135/cropsci1995.0011183X003500020005x

3. Busey P. Wilt avoidance in St. Augustinegrass germplasm. HortScience. 1996; 31(7):1135. https://doi.org/10.21273/HORTSCI.31.7.1135.

4. Atilano RA, Busey P. Susceptibility of St. Augustinegrass germplasm to Pyricularia grisea. Plant Dis. 1983;67(7):782. https://doi.org/10.1094/PD-67782.

5. Huang J, Xia HP, Yang BB. Introduction of a new warm-season turfgrassStenotaphrum helferi Munro. Grassland Turf. 2004. https://doi.org/10.3969/j. issn.1009-5500.2004.02.017.

6. Milla-Lewis SR, Zuleta MC, Van Esbroeck GA, Quesenberry KH, Kenworthy KE. Cytological and molecular characterization of genetic diversity in Stenotaphrum. Crop Sci. 2013;53(1):296. https://doi.org/10.2135/cropsci2012. 04.0234 .

7. Mulkey SE, Zuleta MC, Keebler JE, Shaff JE, Milla-Lewis SR. Development and characterization of simple sequence repeat markers for St. Augustinegrass. Crop Sci. 2014;54(1):401. https://doi.org/10.2135/cropsci2013.04.0246.

8. Kimball J, Zuleta M, Martin M, Kenworthy K, Chandra A, Milla-Lewis S. Assessment of molecular variation within 'Raleigh' St. Augustinegrass using amplified fragment length polymorphism markers. HortScience. 2012;47(7): 839. https://doi.org/10.21273/HORTSCl.47.7.839.

9. Genovesi AD, Jessup RW, Engelke MC, Burson BL. Interploid St. Augustinegrass [Stenotaphrum secundatum (Walt.) Kuntze] hybrids recovered by embryo rescue. Vitro Cell Dev Biol Plant. 2009;45(6):659. https://doi.org/ 10.1007/s11627-009-9230-X.

10. Yu X, Brown JM, Graham SE, Carbajal EM, Zuleta MC, Milla-Lewis SR. Detection of quantitative trait loci associated with drought tolerance in St. Augustinegrass. PLoS One. 2019;14(10):e0224620. https://doi.org/10.1371/ journal.pone.0224620.

11. Payacan C, Moncada X, Rojas G, Clarke A, Chung KF, Allaby R, et al. Phylogeography of herbarium specimens of asexually propagated paper mulberry [Broussonetia papyrifera (L.) L'Hér. Ex vent. (moraceae)] reveals genetic diversity across the pacific. Ann Bot. 2017;120(3):387. https://doi.org/ 10.1093/aob/mcx062.

12. Lee GA, Song JY, Choi HR, Chung JW, Jeon YA, Lee JR, et al. Novel microsatellite markers acquired from Rubus coreanus Miq. And crossamplification in other Rubus species. Molecules. 2015;20(4):6432. https://doi. org/10.3390/molecules20046432.

13. Fiedler JD, Lanzatella C, Okada M, Jenkins J, Tobias CM. High-density single nucleotide polymorphism linkage maps of lowland switchgrass using genotyping-by-sequencing. Plant Genome. 2015;8(2):1. https://doi.org/10. 3835/plantgenome2014.10.0065.

14. Gulsen O, Sever-Mutlu S, Mutlu N, Tuna M, Karaguzel O, Shearman RC, et al. Polyploidy creates higher diversity among Cynodon accessions as assessed by molecular markers. Theor Appl Genet. 2009;118(7):1309. https://doi.org/ 10.1007/s00122-009-0982-9.

15. Huang CQ, Liu GD, Bai CJ, Wang WQ, Zhou SY, Yu DQ. Estimation of genetic variation in Cynodon dactylon accessions using the ISSR technique. Biochem Syst Ecol. 2010;38(5):993. https://doi.org/10.1016/j.bse.2010.09.013.

16. Jiang LF. Diversity of Lolium multiflorum $L$ based on SRAP markers worldwide. Prataculture Anim Husbandry. 2017. https://doi.org/10.3969/j. issn.2096-3971.2017.03.002 
17. Li QY, Zheng GW. Research and application of SNP molecular marker technology in crop seed detection. China Seed Ind. 2019. https://doi.org/10. 19462/j.cnki.1671-895x.20191023.005.

18. Cai L, Yang H, Wang Y, Li YX, Chen GD. Analysis of genetic diversity of tobacco germplasm resources based on SNP markers via genotyping-bysequencing technology. Chin Tob Sci. 2018. https://doi.org/10.13496/j.issn. 1007-5119.2018.05.003.

19. Li C, Ma J, Liu H, Ding PY, Yang CY, Zhang H, et al. Detection of QTLs for spike length and plant height in wheat based on 55K SNP array. J Triticeae Crops. 2019. https://doi.org/10.7606/j.issn.1009-1041.2019.11.03.

20. Li ZY, Yu HL, Fang ZY, Yang LM, Liu YM, Zhuang M, et al. Development of SNP markers in cabbage and construction of DNA fingerprinting of main varieties. Sci Agric Sin. 2018;2018(14):14. https://doi.org/10.3864/j.issn.05781752.2018.14.014.

21. Song W, Wang FG, Tian HL, Yi HM, Wang L, Zhao JR. Identification of maize inbred lines using core SNP loci. J Maize Sci. 2013;4:1 doi: CNKI:SUN:YMKX.0. 2013-04-008.

22. Busey P. Morphological identification of St. Augustinegrass cultivars. Crop Sci. 1986:26(1):28. https://doi.org/10.2135/cropsci1986.0011183X002600010006x.

23. Meng ZN, Zhuang ZM, Jin XS, Tang QS, Su YQ. Analysis of RAPD and mitochondrial 16s rRNA gene sequences from Trichiurus lepturus and Eupleurogrammus muticus in the Yellow Sea. Prog Nat Sci. 2004;14(2):125. https://doi.org/10.1080/10020070412331343251.

24. Zhang R, Tang AJ, Xie JH, Shi FX, Zhao Y. DNA fingerprinting and genetic diversity analysis of Elymus pastures. J North Agric. 2019;47:1-8.

25. Qi JM, Liang JX, Chen MX, Xu JT, Niu XP, Zhou DX, et al. Genetic diversity and evolutionary analysis of tobacco (Nicotiana tabacum L.) germplasm resources based on ISSR and SRAP markers. Acta Agron Sin. 2012;38(8):1425. https://doi.org/10.3724/SP.J.1006.2012.01425.

26. Wang Y, Wan LC, Huang CY, Han JD, Li J, Yang P, et al. Genetic diversity of Grifola frondosa based on integrated ISSR and SRAP analysis. Acta Edulis Fungi. 2019. https://doi.org/10.16488/j.cnki.1005-9873.2019.03.004

27. Shi XL, Chen P, Yu DS, Han RH, Liu P. Analysis of genetic diversity and construction of fingerprint of Pennisetum by SRAP. Guangdong Agric Sci. 2018. https://doi.org/10.16768/j.issn.1004-874X.2018.10.009.

28. Tang $\mathrm{YQ}$, Hu XW, Guo JC, Bai CJ, He XH. An analysis by ISSR of genetic diversities in Stylosanthes germplasms. Acta Pratacul Sin. 2009;18:57-64.

29. Li H, Liu L, Lou Y, Hu T, Fu J. Genetic diversity of chinese natural bermudagrass (Cynodon dactylon) germplasm using ISSR markers. Sci Hortic. 2011;127(4):555. https://doi.org/10.1016/j.scienta.2010.12.001.

30. Liu W, Zhang XQ, Li F, Ma X, Fan Y. Genetic diversity of bermudagrass accessions in south-West China by ISSRs molecular markers and geographic provenance. Acta Pratacul Sin. 2007;16(3):55. https://doi.org/10.3321/j.issn: 1004-5759.2007.03.009.

31. Zhang XY, Liao L, Wang ZY, Bai C, Liu J. Analysis of genetic diversity in Chrysopogon aciculatus using Intersimple sequence repeat and sequencerelated Amplifified polymorphism markers. HortScience. 2016;51:972-9.

32. Jia ZF, Wang QL, Dong N. Phenotype and SSR genetic diversity of upland cotton germplasm resources. Lett Biotechnol. 2019;30:653-61.

33. Qi YC, Bao MZ. Evaluation of genetic relationships of Tagetes patula inbred lines using ISSR markers and morphological traits. Sci Agric Sin. 2007. https://doi.org/10.3321/j.issn:0578-1752.2007.06.020.

34. Liao L, Bai CJ, Guo XL, Wang ZY. Morphological diversity of Chrysopogon aciculatus. Chin J Trop Crops. 2011;32:2042. https://doi.org/10.3969/j.issn. 1000-2561.2011.11.009.

35. Liu JX, He SA, Chen SL. Morphology and types of Zoysia in East China. Acta Agrestia Sinica. 1997. https://doi.org/10.11733/j.issn.1007-0435.1997.01.007.

36. Li H, Durbin R. Fast and accurate short read alignment with burrowswheeler transform. Bioinformatics. 2009;25:1754-60.

37. Li H, Handsaker B, Wysoker A, Fennell T, Ruan J, Homer N, et al. 1000 genome project data processing subgroup. The sequence alignment/map format and SAMtools. Bioinformatics. 2009;25:2078-9.

38. Broad Institute. GATK best practices for the NGS pipeline. (date of access: 19/01/2016); 2016.

39. Tang H, Peng J, Wang P. Estimation of individual admixture: analytical and study design considerations. Genet Epidemiol. 2005;28:289-301.

40. Tamura K, Stecher G, Peterson D, Filipski A, Kumar S. MEGA6: molecular evolutionary genetics analysis version 6.0. Mol Biol Evol. 2013;30(12):2725. https://doi.org/10.1093/molbev/mst197.

41. Patterson N, Price AL, Reich D. Population structure and eigenanalysis. PLoSGenet. 2006;2(12):e190. https://doi.org/10.1371/journal.pgen.0020190.
42. Li G, Quiros CF. Sequence-related amplified polymorphism (SRAP), a new marker system based on a simple PCR reaction: its application to mapping and gene and tagging in Brassica. Theoretucal Appl Genet. 2001;103(2-3): 455. https://doi.org/10.1007/s001220100570.

43. Zietkiewicz E, Rafalski A, Labuda D. Genome fingerprinting by simple sequence repeat (SSR)-anchored polymerase chain reaction amplification. Genomics. 1994;20(2):176. https://doi.org/10.1006/geno.1994.1151.

44. Wang ZY, Liao L, Yuan XJ, Guo H, Guo A, Liu JX. Genetic diversity analysis of Cynodon dactylon (bermudagrass) accessions and cuhivars from different countries based on ISSR and SSR markers. Biochem Syst Ecol. 2013;46:108. https://doi.org/10.1016/j.bse.2012.09.001.

45. Yeh FC, Yang RC, Boyle T. POPGENE version 1.31, Microsoft window-based freeware for population genetic analysis: University of Alberta and Centre for International Forestry Research; 1999. Available: https://sites.ualberta.ca/ fyeh/popgene_download.html.

46. Rohlf FJ. NTSYS pc2.1: numerical taxonomy and multivariate analysis system version 2.1. New York: Applied Biostatistics Inc.; 2000.

47. Sokal RR, Michener CD. A statistical method for evaluating systematic relationships: Univ Kansas Sci. Bull. 1958:38:1409-38.

48. Nei M, Li W. Mathematical model for studying genetic variation in terms of restriction endonucleases. Proc Natl Acad Sci. 1979;76(10):5269. https://doi. org/10.1073/pnas.76.10.5269.

\section{Publisher's Note}

Springer Nature remains neutral with regard to jurisdictional claims in published maps and institutional affiliations.
Ready to submit your research? Choose BMC and benefit from:

- fast, convenient online submission

- thorough peer review by experienced researchers in your field

- rapid publication on acceptance

- support for research data, including large and complex data types

- gold Open Access which fosters wider collaboration and increased citations

- maximum visibility for your research: over $100 \mathrm{M}$ website views per year

At BMC, research is always in progress.

Learn more biomedcentral.com/submissions 